DOI: 10.17707/AgricultForest.61.3.08

Cosmin SALASAN, Dušan PETRIĆ, Romeo BELLINI, Ljiljana PAJOVIĆ,
Miomir JOVANOVIĆ, Aleksandra DESPOTOVIĆ and Igor PAJOVIĆ

\title{
URBAN SOCIAL ANALYSIS AND OPPORTUNITY ASSESSMENT OF NATIONAL SYSTEM FOR MOSQUITO MONITORING IN MONTENEGRO
}

\begin{abstract}
SUMMARY
The paper captures the urban respondents' position with regard to the suitability of implementation of a mosquito monitoring and control system. The captured and assessed components point to the perception of the current state of the affairs, the importance of the topic in terms of health and impact from the family to the economy scale, the current private expenditure to compensate the household level of safety regarding the mosquitos and the diseases they can transport, the readiness and willingness to support the redesigned and implemented system, the shared distribution of responsible actors and their involvement and financial support. The multi-strata sample verifies for validity with the general population and allows the extrapolation of the findings at national level. The findings indicate not only a very high level of awareness and a quantified yet not formulated need for the implementation of the mosquito monitoring and control system but gives precise indication about the estimated readiness of the urban citizens underlining the importance they grant to the impact of the functional system expected.
\end{abstract}

Keywords: social analysis, mosquito monitoring and control system, urban public awareness, supportive readiness and willingness

\section{INTRODUCTION}

The LOVCEN project (Surveillance of invasive and native mosquito vectors and pathogens they transmit in Montenegro) within the HERIC framework occasioned an in-depth analysis of readiness willingness to contribute and support an upcoming national monitoring and control system for mosquitos and MBDs. Although the sampling procedure allowed the coverage and the research analysis of all relevant stakeholders the current paper presents preliminary results on a single stratified category, namely the urban residents. The construction of the approach targeted the most visible aspects focusing on direct and indirect expenditures regarding the past and present expenditure at the level of the household with regard to the researched problem. The core

${ }^{1}$ Cosmin Salasan, Banat University of Agricultural Sciences and Veterinary Medicine "King Michael I of Romania", Timisoara, ROMANIA; Ljiljana Pajović, Miomir Jovanović, Aleksandra Despotović, Igor Pajović (corresponding author: pajovicb.igor@gmail.com) University of Montenegro, Biotechnical Faculty, Podgorica, MONTENEGRO, Romeo Bellini Centro Agricoltura Ambiente Bologna, ITALY and Dušan Petrić, Faculty of Agriculture, University of Novi Sad, Novi Sad, SERBIA.

Note: The authors declare that they have no conflicts of interest. Authorship Form signed online. 
conception of the questionnaires as selected research instrument was centered on the following relevant directions: knowledge and perception about the current regulatory framework; past and present actions in mosquitos control and their impact in terms of quality assessment, efficiency and efficacy; the impact over the tourism sector, the economy and the public health of the mosquitos and the mosquito borne diseases; current expenditure and the readiness to contribute by supporting a national monitoring and control system; the perception about the supporting pillars of the above mentioned system and their share of contribution.

\section{MATERIAL AND METHODS}

Sample and Measure. The population of interest for this study is the general population of Republic of Montenegro. The stratified random sampling was selected as the most appropriate sampling method considering the coverage of the analysis. Beyond the citizens considered the primary beneficiaries of the proposed system, all other relevant stakeholders were included as categories: the municipalities as institutional actors acting in behalf of the communities, key public institutions at national and local level in the field of public health, tourism operators and their organizations. The stratified random sampling was used coupled with the survey by questionnaire in the situation of the citizens and municipalities. The first iteration in questionnaire survey is represented by the fact that while the citizens were random stratified sampled the municipalities required no sampling being all surveyed. As in the case of the municipalities the institutional actors were also not sampled but integrally surveyed by structured interviews. The preliminary results allowed the analysis of 1032 questionnaires from citizens of which the 489 questionnaires from urban residents are the focus of the current paper.

Design and Procedure. The citizens were stratified by three general strata: residence, age and education (or professional background). The sample inclusion was moderated by the availability and the willingness to respond to the questionnaire face-to-face with the enumerators. A two-layered privacy guarantee was provided in written form and conditioned the participation by a signed agreement of the respondent. The decoupled personal data of the respondents were further encoded prior to be recorded in a database exclusively for the variables mentioned above. The collected answers were further modulated with the strata relevance and processed.

Analysis. Having secured the representation and the validity of sample the data was checked for consistency and recording errors prior to proceed with the inferential statistics as choice of analysis. The choice was basically driven by the need to extrapolate the valid opinions/answers at national level, for the general population as of core relevance for the implementation of the future system. The preliminary data used for the purpose of the current paper allowed the crossinterpretation for the urban residents as $47 \%$ of total sample, including answers from non-urban residences (53\%). 


\section{RESULTS AND DISCUSSION}

The urban respondents have a general age distribution as displayed in the Figure 1 with a minor deviation in compliance with the strata criteria generated by the two access criteria stated in design and procedure. The largest number of respondents, almost half (47\%) have an age between 20-40 years, followed by on third (34\%) with ages between $40-60$ years. These figures are indicating that $81 \%$ of the answers can be assimilated as coming from the active population.

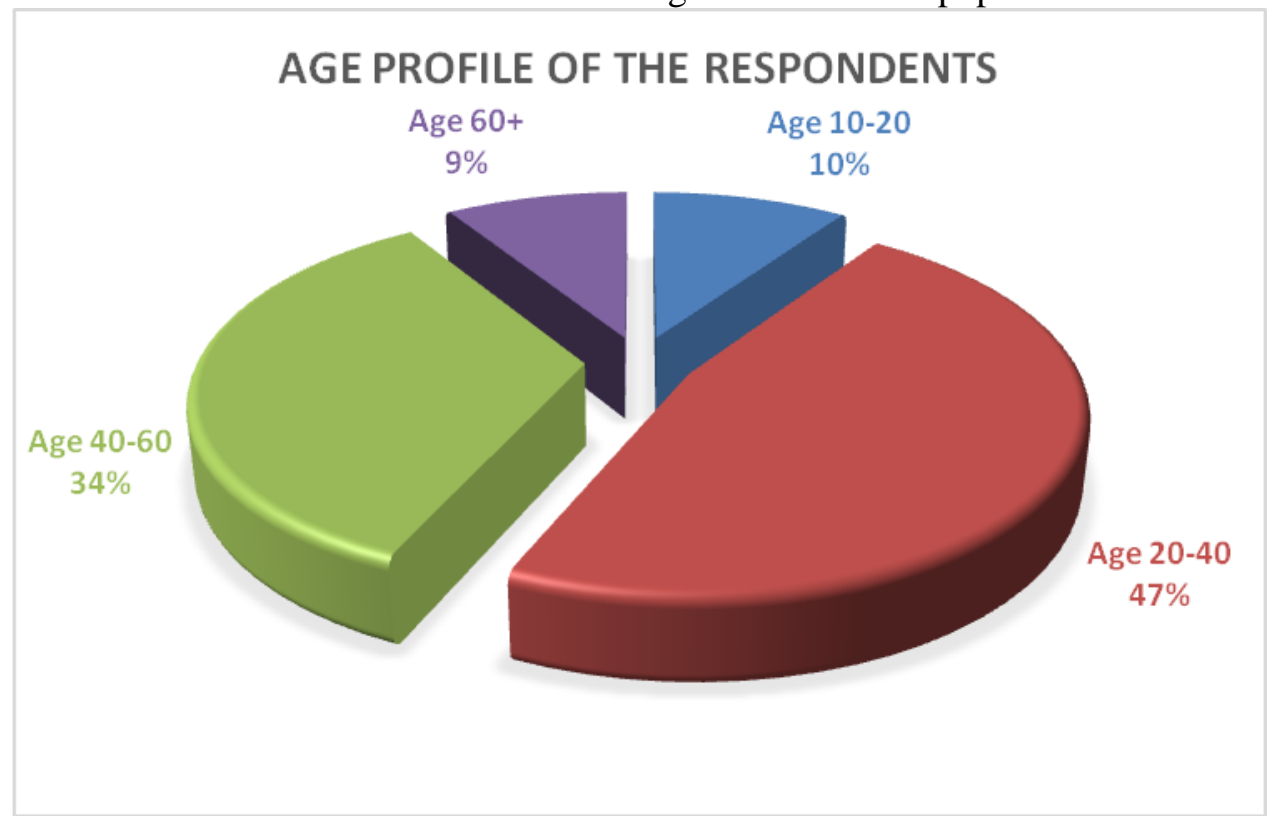

Figure 1 Age profile of the respondents Source: LOVCEN Survey (urban residents only)

\section{EDUCATION PROFILE OF THE RESPONDENTS}

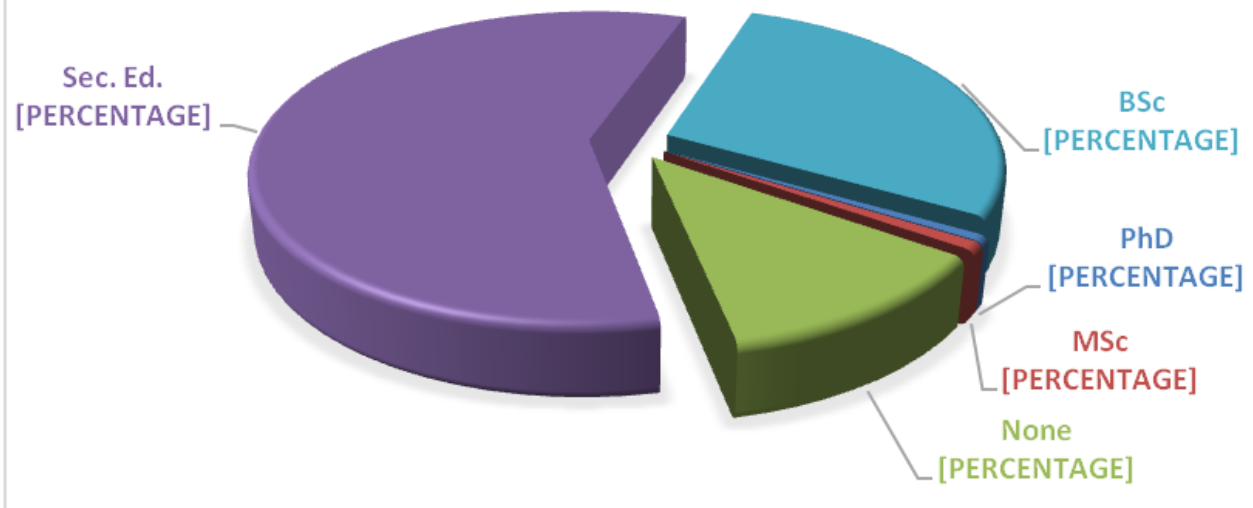

Figure 2 Education profile of the respondents Source: LOVCEN Survey (urban residents only) 
The second major strata represented by the education level of the respondents is illustrated in Figure 2. Almost $60 \%$ of the questioned urban residents have a secondary education level, followed by almost $30 \%$ residents with higher education. This distribution assumes a high level of awareness with regard to the research questions. As observed further in the investigation of the answers provided even the $12 \%$ of non-qualified respondents proved a qualified opinion in respect to the investigated topic.

With regard to the knowledge about an existing and functioning mosquito control system in place, answers meant to underline and reflect the perception about the effectiveness of the current compulsory actions as stipulated by law, the respondents indicate by $59 \%$ no knowledge about any regulative framework. The shares are presented in Figure 3. The findings are strengthen by $97 \%$ of the respondents indicating knowledge of existing mosquito control but with further needs of enhancement in terms of regulative precision with regard to the control and the diseases the mosquitos can transmit.

\section{Is mosquito control regulated by the law?}

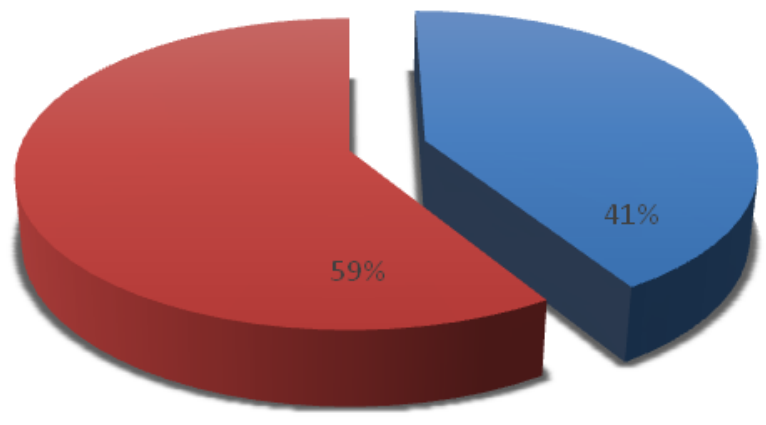

ares no

Figure 3 Knowledge about mosquito control being regulated by law Source: LOVCEN Survey (urban residents only)

As seen for Figure 4 the knowledge about the mosquito control is further explained by indicating the currently used methods: against adults only, against larvae only or against adults and larvae. One quarter of the respondents (24\%) have no knowledge about any control actions while one third (34\%) indicate no control measures used at all. The largest share of identified used methods indicate adult-only mosquito control (40\%) while the larvae-only and adult and larvae measures are identified by $1 \%$ of the respondents each. With a large majority of over $95 \%$ the respondents indicating any knowledge of the control measures used in their municipality estimate that the effectiveness of the used 
measures need to be assessed for effectiveness. Coupled with $95.7 \%$ of respondents indicating the need for mosquito control these answers indicate not only a high awareness but also formulate as a public demand towards responsible authorities. Even the $4.3 \%$ of respondents ( 21 citizens) not identifying a need for the control system have stated that they will definitely change their mind if a dangerous disease transmitted by mosquitos would appear in Montenegro.

\section{Is there mosquito control in your municipality and how it is performed?}

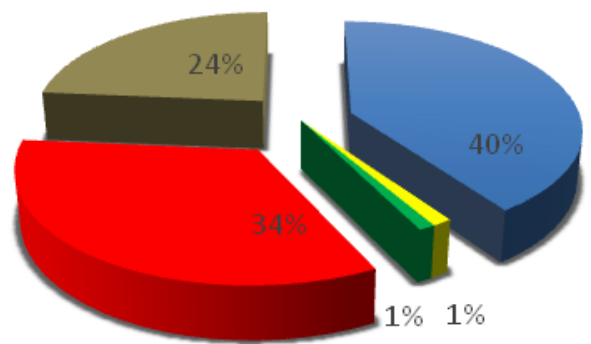

- Adults Larvae Adults and larvae $\quad$ No Don't know

Figure 4 Knowledge about the mosquito control methods used Source: LOVCEN Survey (urban residents only)

Following the trend of the previous answers the quasi-majority of the respondents (over 98\%) would support the initiative of establishing a national monitoring system for mosquito control. At the same time, $97 \%$ of the total urban respondents indicated the need for an independent and objective quality control check of the supported system.

With regard to the current private expenditure at the level of their households the answers of the respondents are illustrated in Figure 5. Although the answers were provided in estimated amounts spent yearly the figures were grouped in the following classes of amounts expressed in Euro: 5-10, 15-20, 2550 and 50-100. The spent amount was further crossed with the age of the respondents. The indicated values, or the column height for each amount category represents the share of respondents in the same age class and not the shares among different age classes. As graphically presented below the youngest part of the respondents have a normal distribution of expenditure with almost $70 \%$ spending up to 10 Euro/year, $20 \%$ going up to 20 Euro/year while little over $10 \%$ spend 25 to 50 Euro/year in private mosquito control at household level. The strata 20-40 years of age have a more leveled expenditure pattern where the difference between the respondents spending 15-20 Euro/year and those spending 
25-50 Euro/year represents less than $4 \%$ of this category respondents. Also, those spending between 25-100 Euro/year in this category cover 30\% of the urban residents in the same category of 20-40 years of age. The most evenly distributed expenditure is observed within the category of 40-60 years of age, where less than $40 \%$ spend up to 10 Euro/year, more than $1 / 4$ of the respondents $(27.27 \%)$ spend $15-20$ or 25-50 Euro/year, while most significantly almost $1 / 10$ spend 50100 Euro/year. The age category over 60 years has a similar expenditure pattern to the youngest age category, massively concentrated in the lowest expenditure class (57.14\%), almost 30\% spending 15-20 Euro/year, $10 \%$ between $25-50$ Euro/year and almost $4 \%$ with an yearly expenditure of 50-100 Euro.

\section{Distribution of amounts spent for extra mosquito control at household level by age classes}

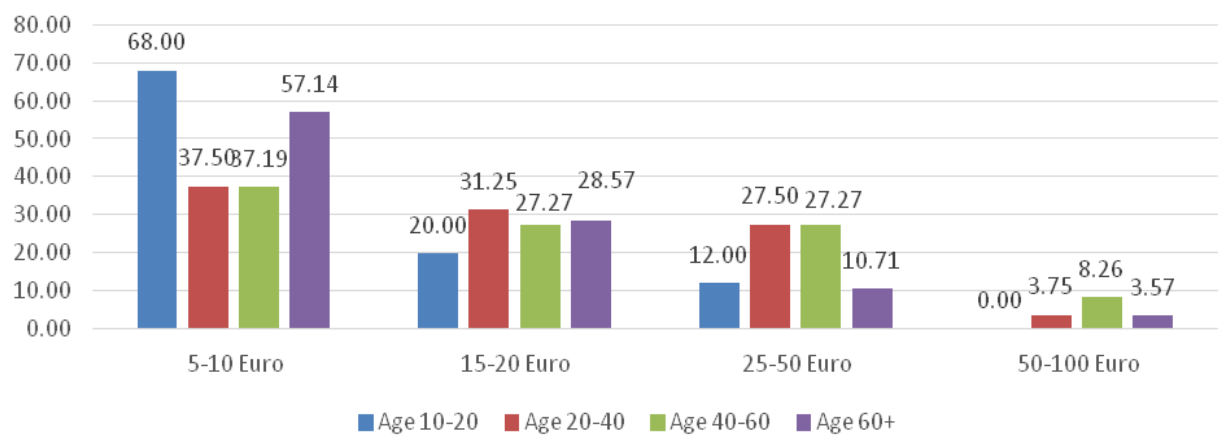

Figure 5 Distribution of amounts spent for extra mosquito control at household level by age classes Source: LOVCEN Survey (urban residents only)

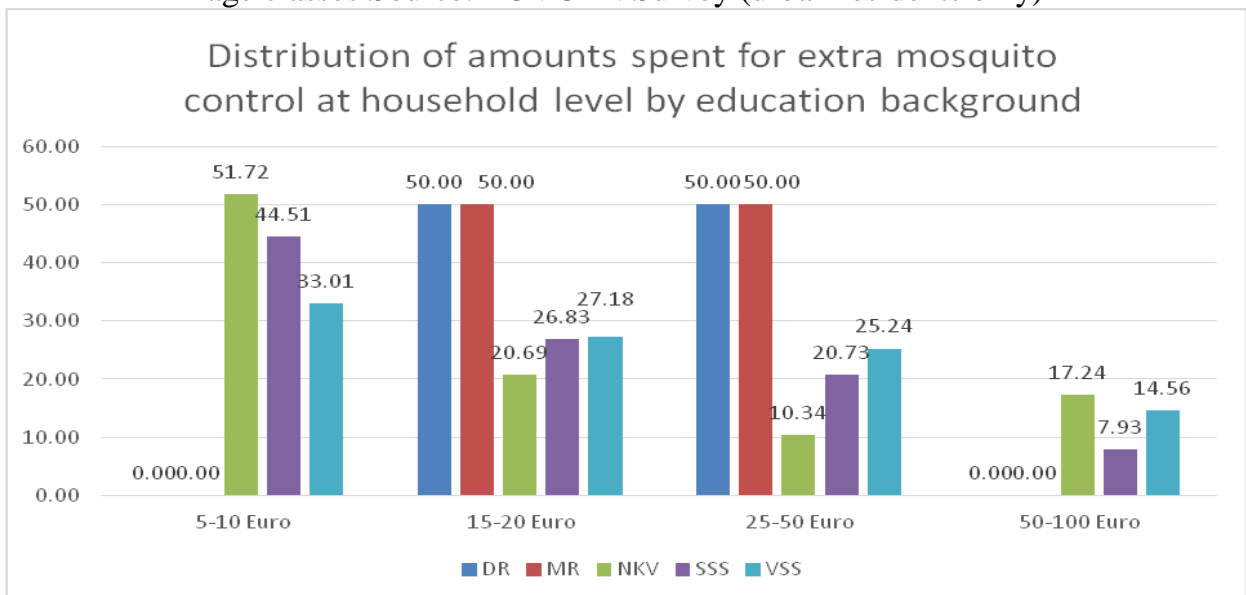

Figure 6 Distribution of amounts spent for extra mosquito control at household level by education background

DR-PhD, MR-MSc., NKV-No qualification, SSS-Secondary education and VSS-BSc

Source: LOVCEN Survey (urban residents only) 
As the expenditure crossed with the age strata returned normal expected distributions as it will be concluded further in this paper crossing the education background with the yearly expenditure levels returns the distributions presented in the Figure 6 below. The same expenditure classes were grouped like in the case of the age classes: 5-10, 15-20, 25-50 and 50-100 Euro/year, and the same expression of results in shares by educational background category were preformed allowing us to observe the class distribution rather than shares of the expenditure class shares. As observed and quantified the respondents with higher educational background (with $\mathrm{PhD}$ or $\mathrm{MSc}$ ) have an equally split expenditure between the classes 15-20 and 25-50 Euro/year. The urban residents with a higher education degree (BSc) have the most tempered expenditure pattern with $1 / 3$ spending up to 10 Euro/year, 1/4 with 15-20 Euro/year, 1/5 spending between 25 and 50 Euro/year while almost $15 \%$ reach levels between 50 and 100 Euro/year. The respondents with secondary education level are distributed between 5-10 Euro/year (almost 45\%), 15-50 Euro/year (over 47\%) and 50-100 Euro/year (almost 8\%). The surprising observation relate to the urban citizens with no education background where $17.24 \%$ of the respondents spend 50-100 Euro/year and 10.34\% spend 25-50 Euro/year for extra mosquito control.

The two thirds of urban respondents willing to financially support a national monitoring and control system for mosquitos and MBDs have a distribution as presented in the Figure 7 bellow according to the estimated expressed amounts indicated as private contribution. Almost $1 / 4$ of the respondents are ready and willing to contribute to 10 Euro/year, over 1/10 with 20 Euro/year while over 5\% could contribute with 30 Euro/year or more. At the same time, over $95 \%$ of the total urban respondents acknowledge that tourism sector could suffer due to mosquitos or diseases carried by mosquitos chasing away the tourists.

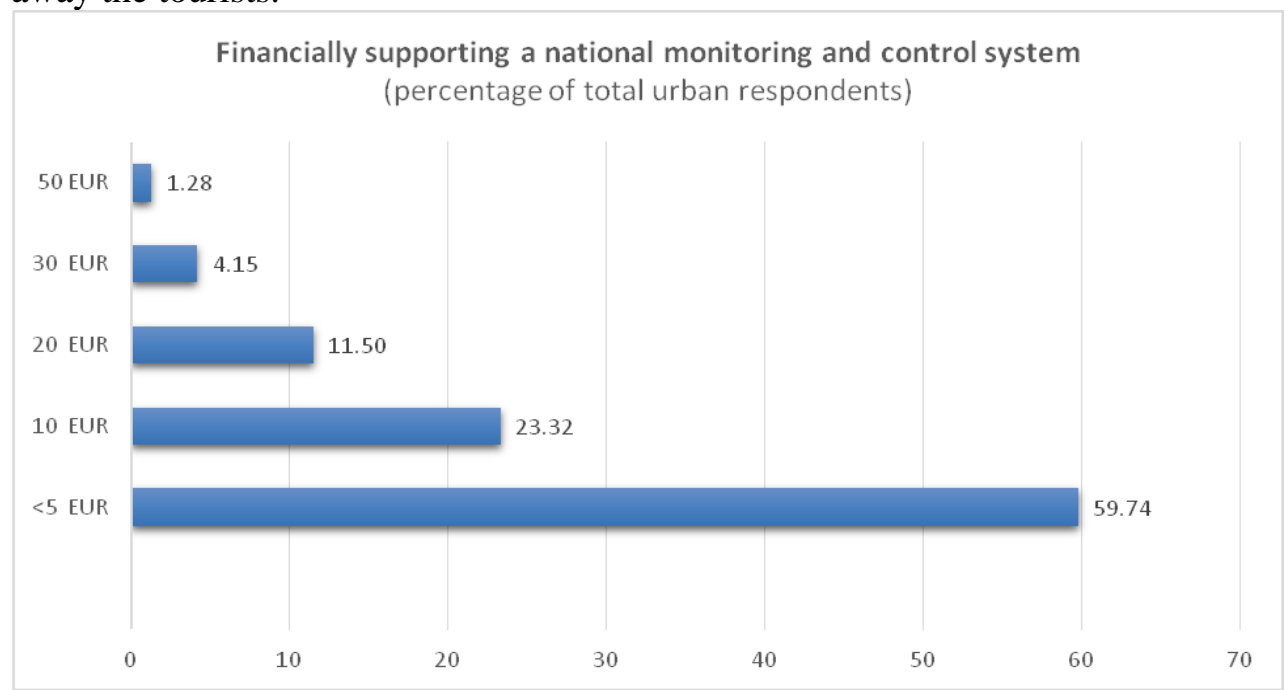

Figure 7 Financially supporting a national monitoring and control system Source:

LOVCEN Survey (urban residents only) 
The respondent's view regarding the potential support offered for the national mosquito monitoring and control system shared between the main categories of actors is presented in Figure 8. In the urban citizens' view the state should contribute with $50-100 \%$ of the systems' needs, $25-50 \%$ should represent the communities (municipalities) contribution while the citizens should cover at most $20 \%$.

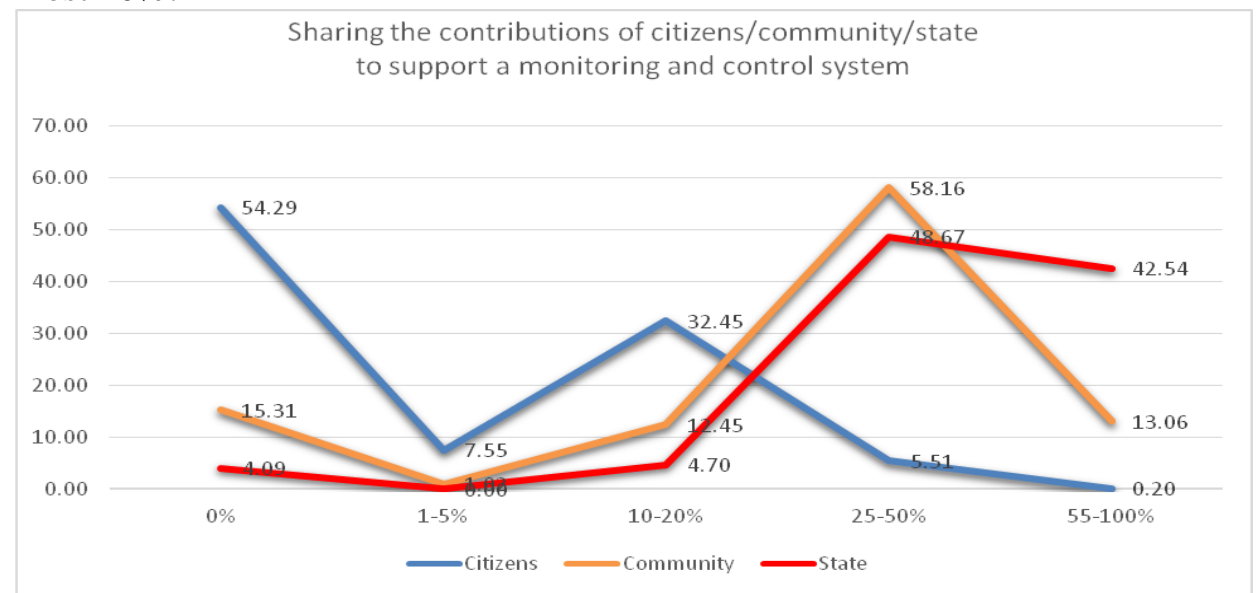

Figure 8 Sharing the contributions of citizens/community/state to support a monitoring and control system

Source: LOVCEN Survey (urban residents only)

\section{CONCLUSIONS}

The multi-stratified urban sample provided a general overview of the awareness and knowledge related to the mosquitos and the MBDs as well as quantifications based on estimates correlated with the expression of interest by the willingness to be an active part and support to the future national mosquito monitoring and control system.

Although expressly regulated and stated in the regulatory framework the present mosquito control is of no knowledge to more than half of the urban residents which rather underlines the lack of communication and public promotion from the side of the authorities than a missing interest of the citizens. This finding articulates well with the LOVCEN implementation aiming to provide a comprehensive pack of communication strategy recommendations attached to the public policy interventions with regard to the mosquito control system.

In-line with the previous observation, the visibility of the current mosquito control actions reflects in the answers of the questioned urban citizens as $1 / 4$ of them have no knowledge of such actions around them while $1 / 3$ precisely indicate there are no such actions undertaken until present. In this respect, the perception of these 58\% of the urban residents underline clear need of intervention, both in action and visibility.

The overwhelming majority of answers (over 95\%) of those indicating any 
knowledge of the control measures stress the need for addressing the assessment and the effectiveness of the used measures. Further extrapolated with the $95.7 \%$ of respondents indicating a clear need for mosquito control these answers indicate not only a high awareness but also formulate as a public demand towards responsible authorities since even the extremely small number of respondents not identifying a need for the mosquito control system can foresee the threat and would most definitely change their mind with regard to the necessity of the system.

Following the logic of the current stated position of the respondents over 98\% of them would support the establishment and the implementation of a national mosquito monitoring and control system while $97 \%$ of the total urban respondents expressly stated the need for an independent and objective quality control along with the implementation of the system.

Although the income levels of the respondents were not collected the patterns drawn by age and education background strata show relatively high amounts spent for mosquitos extra control actions at the level of the household. The annual estimations offered by the respondents follow the income/expenditure trend by age as youngsters and elderly people spend less as they can afford less while active and wealthy age categories spend accordingly. Over $50 \%$ of all respondents with 20 to 40 years of age spend systematically more than 15 Euro/year while over $30-35 \%$ (of the same category in total) spend more than 25 Euro/year for the private extra control, with a peak of almost 1/10 spending 50100 Euro/year. This quantified level of expenditure is the most precise indication for the system implementation need greatly influencing the readiness and the willingness to be actively involved, participate and support the future monitoring and control system.

The education background of the respondents influences differently their expenditure levels, as expected. The surprisingly high share of respondents with no education degree (17.24\%) spending 50-100 Euro/year could be explained by the location of their residences that is a qualified assumption as the information is not recorded in the database. Also, the relatively large shares of respondents with secondary and tertiary (BSc) education spending 5-10 Euro/year could be assimilated to an arbitrary under-estimation of the mounts considering the indicated time-frame of 12 months. Adding to the previous findings regarding the private expenditure for extra mosquito control measures (crossed with the age categories) the amounts are highly important and stress towards the above mentioned system implementation.

The readiness of financially supporting the national monitoring and control system for mosquitos and MBDs shows not only willingness but also commitment as one third of the respondents foresee 10 or 20 Euro/year availability while $5 \%$ could advance to 30 or 50 Euro/year. Coupled with the earlier findings this availability could represent a cut on the private expenditure for the $60 \%$ estimating their own contribution up to 5 Euro/year or a transfer of the current expenditure to the system. 
Decoupled from the amounts estimated as supporting contribution the urban respondents design a fair share distribution for the system support between the state, the communities or the municipalities and the citizens as private actors. The 50\% (state) / 30\% (municipalities) / 20\% (citizens) as general indicated trend underline the acknowledgment of involvement and responsible action with regard to the mosquito control and monitoring system.

The analysis based on observations and findings builds on the foundation of the socially verified need and invites for intervention by the implementation of the targeted system. Final results of the survey including citizens from rural and semi-urban areas, municipalities as actors, public heath institutions at all levels will validate the results of the analysis system-wide and provide the grounds for immediate action at all levels as stated in the implementation roadmap of the LOVCEN project.

\section{REFERENCES}

Arksey Hilary, Collecting data through joint interviews, Social Research Update, http://sru.soc.surrey.ac.uk/SRU15.html, 09.2015

Farrall S., Bannister J., Ditton J., Gilchrist Elizabeth, Open and Closed Question, Social Research Update, http://sru.soc.surrey.ac.uk/SRU17.html, 09.2015

Fielding Jane \& Gilbert N., Understanding Social Statistics (2nd edition), Sage, 2006

Grinyer Anne, The Anonymity of Research Participants: Assumptions, Ethics and Practicalities, Social Research Update, http://sru.soc.surrey.ac.uk/SRU36.html, 09.2015

Neuendorf Kimberly, The Content Analysis Guidebook, Sage, 2002

Salasan C., Pajovic Ljiljana, Dragicevic Snezana, Jovanovic M., Despotovic Aleksandra, Pajovic I., Petric D., LOVCEN Social Analysis Report, http://project-lovcen.me/page.php?id=11, 09.2015

De Vaus, D.A., Surveys in Social Research, Routledge, 2002

Free Resources for Program Evaluation and Social Research Methods, http://gsociology.icaap.org/methods/, 09.2015

Research Methods Knowledge Base for Social Research Methods, http://www.socialresearchmethods.net/kb/index.php, 09.2015 